\title{
REPRESENTAÇÕES SOCIAIS SOBRE EDUCAÇÃO AMBIENTAL EM GRUPOS DA TERCEIRA IDADE
}

\author{
Social representation of environmental education \\ by third age groups
}

\author{
Érica S. Miranda ${ }^{1}$ \\ Virgínia T. Schall ${ }^{2}$ \\ Celina M. Modena ${ }^{3}$
}

Resumo: Este estudo buscou compreender os sistemas de significação socialmente construídos e compartilhados por grupos de idosos residentes em área urbana da região metropolitana de Belo Horizonte, Minas Gerais, sobre temas ambientais. A teoria das representações sociais foi o referencial que orientou o trabalho, na direção de um estudo comparativo entre dois grupos de terceira idade: o grupo Fonte de Vida, de Belo Horizonte, e o Clube Viver Melhor, do município de Betim. Foram entrevistados vinte idosos e as entrevistas foram analisadas na perspectiva da análise de conteúdo. As representações mostraram que os idosos têm percepção da degradação ambiental e apostam na cooperação, solidariedade e educação, em sentido amplo, e em sua participação como atores sociais, em contextos singulares, para o despertar de uma sensibilização ambiental.

Palavras-chave: Educação Ambiental. Terceira idade. Meio ambiente. Representação social.

\begin{abstract}
The present study was dedicated to understanding the system of meanings socially constructed and shared by Third Age groups of people living in urban areas of the metropolitan region of Belo Horizonte, Minas Gerais State, Brazil. The theory of social representation was employed as a theoretical parameter to make comparisons between two third age groups, the Fonte Vida group from Belo Horizonte and the Clube Viver Melhor group from Betim. Twenty older citizens were interviewed and the outcomes analyzed using the content analysis. The representations showed that older people have understandings of environmental degradation and look broadly for cooperation, solidarity and education, in their participation as social players, and in a singular context, for ecological sensitization.
\end{abstract}

Key words: Environmental education. Elderly. Environmental. Social representation.

\footnotetext{
${ }^{1}$ Mestre em Ensino de Biociências; Fundação Oswaldo Cruz (Fiocruz). Belo Horizonte, MG. $<$ miranda@cpqrr.fiocruz.br>

${ }^{2}$ Doutora em Educação; pesquisadora; chefe do Laboratório de Educação em Saúde, Instituto René Rachou, Fundação Oswaldo Cruz (IRR/Fiocruz). Belo Horizonte, MG. <vtschall@cpqrr.fiocruz.br>

${ }^{3}$ Pós-doutora em Saúde Coletiva; pesquisadora visitante, Laboratório de Educação em Saúde, Instituto René Rachou, Fundação Oswaldo Cruz (IRR/Fiocruz). Belo Horizonte, MG. <celina@cpqrr.fiocruz.br>
}

${ }^{1}$ Instituto René Rachou, Laboratório de Educação em Saúde
Av. Augusto de Lima, 1715
Barro Preto - Belo Horizonte, MG
30.190-002
Ciência \&̊ Educação, v. 13, n. 1, p. 15-28, 2007 


\section{Introdução}

Em um contexto marcado pela degradação ambiental, reflexões sobre as práticas sociais articuladas à relação indivíduo-natureza e aos riscos ambientais devem ser prioritárias para a construção de uma sociedade mais eqüitativa na perspectiva da ecocidadania e da sustentabilidade (RANCHE e TALAMONI, 2005; JACOBI, 2003). Diversos discursos atrelando a dimensão econômica e social da questão ecológica têm sido apresentados. O discurso econômico e técnico-científico, que não privilegia as considerações éticas e políticas associadas à justiça social e participação política, ocupa uma posição privilegiada na matriz interpretativa da relação homem-natureza.

Embora germes do discurso da sustentabilidade possam ser identificados em contextos históricos remotos, suas expressões mais recentes talvez sejam observadas nos princípios da década de 1970. Pode-se observar que o discurso da sustentabilidade surgiu como substituto ao do desenvolvimento econômico, produzido e difundido pelos países centrais do capitalismo. As referências mais explícitas à noção de desenvolvimento sustentável estão sistematizadas nos trabalhos do economista Ignacy Sachs, que desenvolveu a noção de Ecodesenvolvimento, a qual propõe uma estratégia multidimensional e alternativa de desenvolvimento que articule promoção econômica, preservação ambiental e participação social. Entretanto, existem matrizes que se identificam com os princípios de que uma sociedade civil organizada tem papel determinante na construção e implementação de conceitos e de práticas voltadas para o meio ambiente (LIMA, 2003).

Nessa direção, coloca-se o papel da educação como proposta transformadora do quadro atual da crise ambiental. Ela seria capaz de estabelecer um processo contínuo pelo qual os indivíduos perceberiam, reflexiva e criticamente, os mecanismos sociais, políticos e econômicos estabelecidos na nova dinâmica global. Com isso, o cidadão teria seus direitos exercidos, plena, responsável e conscientemente, por meio dos vários canais de participação (DIAS, 2004a).

Assim, a educação é convocada a promover o acesso sócio-econômico dos excluídos, a partir da criação de formas mais justas de inserção dos indivíduos em uma sociedade que se pretende igualitária. Para tal, o conceito de educação, voltado durante muito tempo prioritariamente para os processos de ensino-aprendizagem exclusivo das unidades escolares formais, tende a se ampliar. Assim, transpõe os muros da escola, alargando-se para os espaços da casa, do trabalho, do lazer, entre outros. Com isso, um novo campo da educação se estrutura: o da educação não-formal (GOHN, 1999).

Bianconi e Caruso (2005) definem a educação não-formal como qualquer tentativa educacional organizada e sistemática que se realiza, normalmente, fora dos quadros do sistema formal de ensino. A educação não-formal originou-se da fragmentação da educação popular: por um lado ganhou uma nova vitalidade no interior do estado, diluindo-se em suas políticas públicas e, por outro, continuou como educação não-formal, dispersando-se em milhares de pequenas experiências (GADOTTI, 2000).

Em 1960 nasce o Movimento de Cultura Popular, com intuito de combater o analfabetismo e promover a elevação do nível cultural do povo. Nos anos 1970, Coombs e Ahmed definiram a educação não-formal como "uma atividade educacional organizada e sistemática, levada a efeito fora do marco de referência do sistema formal, visando propiciar 
Representações sociais sobre educação ambiental...

tipos selecionados de aprendizagem a subgrupos particulares da população, sejam estes adultos ou crianças" (GOHN, 1999, p. 91).

$\mathrm{Na}$ década de 1990, Gohn designa a educação não-formal como um processo com quatro campos ou dimensões, que correspondem às suas áreas de abrangência:

O primeiro envolve a aprendizagem política dos direitos dos indivíduos enquanto cidadãos (...). O segundo, a capacitação dos indivíduos para o trabalho, por meio da aprendizagem de habilidades e/ou desenvolvimento de potencialidades. O terceiro, a aprendizagem e exercício de práticas que capacitam os indivíduos a se organizarem com objetivos comunitários, voltados para a solução de problemas coletivos cotidianos (...). O quarto é a aprendizagem dos conteúdos da escolarização formal, escolar, em formas e espaços diferenciados (GOHN, 1999, p. 98-99).

Essa tendência vem sendo apontada por vários autores que discutem a ampliação dos espaços sociais de educação para além da escola. Hoje existem distintos loci de produção da informação e do conhecimento, de criação e de reconhecimento de identidades e práticas culturais e sociais. Percebe-se, assim, a caracterização de diferentes "ecossistemas educativos", novos espaços-tempo de produção de conhecimento necessários para formação de cidadanias ativas. No atual contexto, em que a sociedade apresenta demandas sócio-educacionais que ultrapassam os limites formais e regulares da escola, é importante esclarecer que as intervenções não-formais - no início relacionadas a projetos de educação popular desarticulados ou a projetos exclusivamente assistencialistas - têm se transformado, passando a incluir discussões sobre políticas sociais públicas para os setores específicos. A própria sociedade civil passa a participar desse debate, ainda que de maneira restrita, e a assumir responsabilidades práticas (GOHN, 1999).

Contemporaneamente tem-se observado o crescimento da população idosa e sua concentração nas áreas urbanas. Tal crescimento é explicado por dois processos: a queda da fecundidade, que modificou a distribuição etária da população brasileira, e a redução da mortalidade da população idosa, trazendo, como conseqüência, o aumento no tempo vivido. Tais processos vêm ocorrendo muito rapidamente, fazendo eco no panorama mundial, o que revela indicadores positivos de uma melhora de qualidade de vida da população (CAMARANO, 2002). No início deste milênio, o acelerado crescimento da população idosa brasileira surge como elemento central para a elaboração de novas políticas públicas (UCHÔA, 2003). A cada ano que passa, mais 650 mil idosos são incorporados à população. O Brasil já perdeu muito tempo acreditando que ainda era um país jovem, sem dar o devido crédito às informações demográficas que mostravam e projetavam o envelhecimento de sua população (LIMA-COSTA e VERAS, 2003).

Os grupos de terceira idade têm sido apontados como alternativas para melhorar a qualidade de vida, autonomia e independência dos idosos. Estudos envolvendo ampla revisão da literatura, no período de 1998 a 2004, concluíram que estes espaços minimizam os efeitos do envelhecimento por meio da sociabilidade, do apoio social, das interações e oportunidades de vivências coletivas (JOÃO et al., 2005). O processo de grupo estabelece múltiplas relações entre seus componentes: o indivíduo se entrega ao grupo, tornando-se membro operante e 
Miranda, É. S. et al.

transpondo, para sua família e comunidade, conhecimentos construídos no processo grupal (ZIMERMAN, 2000).

Os idosos podem tornar-se interlocutores de práticas e idéias, influenciando seu contexto familiar e social, como demonstrado por Miranda et al. (2005). Nesse sentido, foi objetivo deste trabalho descrever a representação social de idosos sobre a temática ambiental, considerando-se as interlocuções entre terceira idade, meio ambiente e as possibilidades da educação não-formal na construção de uma participação social para o desenvolvimento ou potencialização de uma sensibilização ambiental ${ }^{4}$.

\section{Metodologia}

O referencial teórico-metodológico que orientou este estudo foi o das representações sociais, entendidas como modalidades de conhecimento prático orientadas para a comunicação e compreensão do contexto social, material e ideativo. São formas de conhecimento que se manifestam como elementos cognitivos - imagens, conceitos, categorias, teorias - mas que não se reduzem, jamais, a eles. Pertencem a um campo transdisciplinar, pois podem ser abordadas como representações mentais, estudadas pela Psicologia Cognitiva e Psicanálise, representações públicas, objeto de estudo da Psicologia Social, e representações culturais, objeto de estudo da Antropologia, o que se assemelha à Epidemiologia numa perspectiva das representações em determinada população (SPINK, 2002, 1993).

A palavra representação, associada aqui ao sentido de reprodução daquilo que se pensa, enfatiza a natureza do conhecimento numa perspectiva que remete aos estudos clássicos sobre ideologia introduzidos pelo historicismo e pelo relativismo, abrindo caminho para o paradigma construtivista (SPINK, 2002, 1993). As representações sociais definidas como formas de conhecimento prático inserem-se mais especificamente entre as correntes que estudam o conhecimento do senso comum. As correntes que se debruçam sobre os saberes enquanto saberes, quer formalizados ou não, procuram superar a clivagem entre ciência e senso comum. Tal perspectiva amplia o olhar de que este conhecimento também é legítimo e motor das transformações sociais. A palavra representação também pode significar uma interpretação. Nesta perspectiva, não é mais a natureza do conhecimento que está em pauta, mas suas implicações práticas. O conhecimento estudado via representações sociais é sempre uma forma comprometida e/ou negociada de interpretar a realidade (SPINK, 2002, 1993).

As representações sociais são campos socialmente estruturados na interface de contextos sociais de curto e longo alcances históricos. O contexto social de longo alcance é

\footnotetext{
${ }^{4}$ A sensibilização ambiental é uma ferramenta fundamental para a mudança comportamental em relação ao meio ambiente. Pretende atingir uma predisposição da população para uma mudança de atitudes. No entanto, esta mudança só ocorre se a população for educada, ou seja, se depois de sensibilizada forem apresentados a ela os meios da mudança que levem a uma atitude mais correta em relação ao ambiente.

$<$ http://www.naturlink.pt/ canais/Artigo.asp?iArtigo=9619\&iLingua=1>
} 
Representações sociais sobre educação ambiental...

denominado imaginário social, o conjunto cumulativo das produções culturais que circulam numa determinada sociedade sob as mais variadas formas: iconografia, literatura, canções, provérbios e mitos. Se, de um lado, buscamos os elementos mais estáveis, aqueles que permitem a emergência de identidades compartilhadas, de outro trabalhamos com o que há de diferente, diverso e contraditório no fluxo do discurso social (SPINK, 2002, 1993).

Sob a perspectiva do referencial teórico-metodológico da teoria das representações sociais, dois grupos de terceira idade foram selecionados mediante critérios prévios características sócio-econômicas, classe social, tipo de agremiação, residentes em área urbana. A amostra teve como critério básico a capacidade de refletir o conjunto de experiências que se pretendia demonstrar com a pesquisa (MINAYO, 2000). Os selecionados foram: Grupo Fonte de Vida, do Serviço Social do Comércio (SESC/MG), localizado em Belo Horizonte, e Clube Viver Melhor, da Associação de Proteção à Maternidade, Infância e Velhice (APROMIV), do município de Betim. O critério de escolha não foi numérico. A seleção dos grupos teve como critério básico a capacidade de refletir o conjunto de experiências que vêm sendo desenvolvidas na sociedade, a partir da década de 1990, pela formação dos grupos da terceira idade. Enquanto na experiência do grupo Fonte de Vida predominam atividades físicas, de lazer, e as relações sociais, no grupo Viver Melhor observa-se um propósito de assistência ao idoso. Além disso, são grupos de populações de realidades sociais diferentes: o grupo Fonte de Vida é urbano e o Viver Melhor, de representação mista - urbano e rural.

Um outro critério utilizado foi o da conveniência, ou seja, a aceitação para participar da pesquisa, uma vez que o projeto foi apresentado a outros grupos de terceira idade na região metropolitana de Belo Horizonte. Quanto à eleição dos sujeitos, observaram-se os critérios recomendados por Minayo (2000, p. 102) para pesquisas qualitativas:

deter os atributos que se pretende conhecer com a pesquisa; considerar em número suficiente para permitir reincidência das informações, não desprezando informações ímpares; considerar que na homogeneidade o conjunto de informantes possa ser diversificado para a apreensão de diferenças e semelhanças.

Considerando-se tais critérios vinte idosos foram entrevistados, segundo roteiro semiestruturado que incluía os seguintes aspectos: conhecimentos sobre meio ambiente, cidadania, preservação da natureza, educação ambiental e sustentabilidade. Em ambos os grupos as entrevistas foram individuais e gravadas para posterior análise.

As entrevistas foram submetidas a análise temática de conteúdo a partir de critérios apontados por Bardin (1977): procurar conhecer o que está por trás das palavras; buscar compreender o sentido da comunicação; desviar o olhar para outra significação, outra mensagem através ou ao lado da primeira.

Após as entrevistas observou-se demanda por uma atividade mais prática, que permitisse aos participantes refletir sobre a questão ambiental. Optou-se, então, por uma oficina sócio-educativa que, enquanto método de intervenção, foi construída pelos critérios teóricometodológicos sugeridos por Afonso (2003): a demanda, o foco, o enquadre e a flexibilidade. Obedeceu-se, também, a alguns critérios utilizados para a elaboração de programas educativos, como, por exemplo: adequação da linguagem, estudo do perfil dos participantes, escolha de 
Miranda, É. S. et al.

temas adequados ao nível educacional do grupo e de temas geradores - que mobilizam o grupo porque se relacionam à sua experiência, tocam em suas necessidades, seus medos e conflitos, suas alegrias e possibilidades, aguçam o desejo de participação e troca.

Este projeto foi submetido ao Comitê de Ética em Pesquisa em Seres Humanos do Centro de Pesquisa René Rachou/Fiocruz. Todos os participantes foram convidados a participar do estudo em caráter voluntário e aqueles que aceitaram assinaram um Termo de Consentimento, após receberem as informações sobre o projeto.

\section{Resultados e discussão}

\section{Características dos grupos e dos entrevistados}

O grupo "Fonte de Vida" pertence ao Serviço Social do Comércio (SESC/MG), unidade de serviço Floresta, em Belo Horizonte, Minas Gerais. O SESC/MG trabalha com a terceira idade desde 1989. O “Clube Viver Melhor" pertence à Associação de Proteção à Maternidade, Infância e Velhice (APROMIV), entidade sem fins lucrativos fundada em maio de 1971, com objetivo de assistir e amparar a maternidade, infância e velhice no município de Betim, Minas Gerais.

Observou-se que os dois grupos diferiram nas características sócio-demográficas. No grupo Fonte de Vida, os entrevistados pertenciam à faixa etária entre 59-71 anos, sendo quatro do sexo masculino e seis do sexo feminino. Em relação à escolaridade, três cursaram até a quarta série do Ensino Fundamental, três até o Ensino Médio, outros três tinham o Ensino Fundamental completo e um, o Ensino Superior. Àquela época apenas um continuava trabalhando. Os outros, quando trabalhavam, exerciam as seguintes funções: bancário, costureira, rádio comunicação, ferroviário, artesão, caixa de padaria e licenciatura. Oito recebiam aposentadoria e cinco não possuíam outra fonte de renda. Todos possuíam casa própria: quatro moravam sozinhos, três, com os filhos e o cônjuge, dois moravam apenas com os filhos e um morava apenas com o cônjuge. Cinco eram viúvos, quatro, casados, e um era solteiro. No Clube Viver Melhor, os entrevistados pertenciam à faixa etária entre 60-77 anos, sendo apenas um do sexo masculino e nove do sexo feminino. Em relação à escolaridade, cinco cursaram até a quarta série do Ensino Fundamental, quatro até o Ensino Médio e um não estudou. Nenhum continuava trabalhando, mas, quando trabalhavam, exerciam as seguintes atividades: empregada doméstica, costura, faxina, gari e operador de máquinas pesadas. Na época do estudo, oito recebiam aposentadoria e sete não possuíam outra fonte de renda. Nesse grupo, cinco não possuíam casa própria, cinco moravam sozinhos, dois, com os filhos, outros dois, somente com o cônjuge e um morava com o cônjuge e os filhos. Três entrevistados eram viúvos, quatro, separados, e três, casados.

Comparando-se os grupos, constata-se que os entrevistados do Fonte de Vida eram mais jovens e possuíam nível de escolaridade e status sócio-ocupacional superiores aos do Clube Viver Melhor. Ambos apresentavam número de homens e mulheres equivalente e um elemento comum: o estado civil. A bagagem educacional e inserção social dos sujeitos podem estar associadas a suas representações sociais diferenciadas.

De maneira geral, as variáveis sócio-demográficas descritas refletiram o perfil da 
Representações sociais sobre educação ambiental...

população idosa brasileira, como postulado por Veras (1994), que discute o processo de envelhecimento populacional brasileiro e suas conseqüências e repercussões sociais e econômicas. Para o autor, considerar uniforme a estrutura social, econômica e demográfica de um país como o Brasil, nos desenhos de projetos, é um erro metodológico. Desenhos que não considerem a heterogeneidade de grandes metrópoles não conseguem captar corretamente as reais necessidades e demandas dos diferentes grupos sociais. Em seu estudo, o autor aponta que em 2000 o número de idosos brasileiros na faixa etária entre 60-79 anos era superior ao daqueles com mais de oitenta anos; e que, no país, a distribuição da população idosa segundo sexo, idade e estado civil segue a tendência internacional. Revela, ainda, que uma grande proporção de pessoas idosas vivem sozinhas, particularmente as mulheres $(72 \%)$. O censo de 1980 constatou que 1,8 milhão de pessoas com mais de sessenta anos estavam empregadas e que os idosos possuíam poucos anos de educação formal, existindo diferenças claras entre os sexos e as faixas etárias em relação à alfabetização.

\section{Discutindo ambiente e natureza}

Quanto à produção de significados, a análise das representações sociais buscou identificar as concepções em relação à questão ambiental. Emergiu, como aspecto comum, a degradação atual da natureza: "se a natureza não for preservada o que vem, por exemplo, o calor em excesso, o ar que respiramos fica como se diæ, fica mais poluido"; "Ah, preservar não só pra um futuro, mas atualmente pra que a gente não fique sem ar, sem água que é o principal". Aqui vamos ao encontro do discurso de Dias (2004b), que aponta que o meio ambiente não é formado apenas por flora e fauna, água, solo e ar, como tradicionalmente definido: faz-se necessário considerar aspectos políticos, éticos, econômicos, sociais, ecológicos e culturais para uma visão global do problema e das alternativas de soluções. Neste sentido, observou-se uma diferença nos dois discursos. Os entrevistados do grupo Fonte de Vida apresentaram uma concepção de natureza degradada ou em processo de degradação: "poluição sonora (...) carros velhos soltando fumaceira (...) arpoluido (...) saco de lixo nas ruas (...) lixo nos córregos e rios (...) aumento de população (...) falta de controle (...) devastação (...) vai acabar com a vida". No Clube Viver Melhor, percebeu-se uma representação de natureza edenizada. É uma percepção que destaca, em algumas falas, a concepção de Deus como criador: "preservar a natureza é cuidar das coisas pra ela ficar bonita, bela, em nome de Deus. Tudo no mundo, tudo que nós temos que Deus deu é pra gente cuidar e se a gente cuidar a gente não tem". De maneira geral, a percepção da natureza esteve associada à concepção de estética e paz, como já destacadas por Silva et al. (2005).

O que se pôde observar em comum nos discursos é que a natureza está sendo destruída por um homem descolado de seu contexto e de um modelo de desenvolvimento, ao qual ele não pertence: “(...) se a pessoa vive em lugar onde ele tem o minimo (...) se ele tem pelo menos o local de morar, se (...) tem esgoto"; "O que tinha que fazeré é dá jeito de botar a pessoa num lugar que ela possa plantar, que ela possa vender (...) é aquela história, não adianta dá o peixe, tem que dá a vara e botar ele para pescar".

A poluição atmosférica esteve muito presente como estruturante da representação sobre meio ambiente, significado que talvez seja produto da inserção urbana dos grupos, pois, em espaços rurais, a percepção dos idosos sobre meio ambiente é dada pelos elementos telúricos (MIRANDA et al., 2005). 
Miranda, É. S. et al.

\section{Discutindo a cidadania}

A Política Nacional de Educação Ambiental traz como um de seus objetivos fundamentais "o fortalecimento da cidadania, o incentivo à participação individual e coletiva, permanente e responsável, na preservação do equilíbrio do meio ambiente, entendendo-se a defesa da qualidade ambiental como um valor inseparável do exercício da cidadania" (BRASIL, 1999). As entrevistas tentaram articular o termo cidadania à educação ambiental. Pretendia-se dialogar com o conceito de ecocidadania, buscando averiguar se este estava associado à educação e quais os limites e as possibilidades da educação ambiental na construção de um olhar ecológico. As falas demonstraram percepção de uma sociedade marcada por diferenças sócio-econômicas extremas, pela desigual efetivação do direito, e por outras iniqüidades, embora, não raro, tenham apresentado a noção de pátria como adjetivos que transparecem limitações da noção de cidadania: "eu sou cidadã, né, sou brasileira e amo minha pátria"; "cidadania são os mais grandes, só aqueles de alto gabarito (...) hoje a gente tem um cartão que chama cartão cidadão (...) inclusive do gás nós temos e se nós temos esse cartão, que chama cartão cidadão, essa cidadania já é para todos".

Ao falar de cidadania, a primeira dificuldade consiste no pressuposto da existência de certo consenso para definir aquilo que deve ser compreendido como cidadania moderna. Para Lavalle (2003), falar em cidadania moderna corresponde, no terreno da história, a remeter aos complexos processos de edificação dos Estados-nação. Não foi objeto deste estudo discutir o status sócio-político da cidadania dentro da lógica de dominação do Estado-nação.

Para além dessas questões, procurou-se descobrir em quais pressupostos normativos se alicerça, simbolicamente, o reconhecimento da ecocidadania nos grupos estudados. Para os participantes da pesquisa, confluem na "definição da cidadania" diversos fenômenos passíveis de ser aglutinados sinteticamente em processos de duas ordens: aqueles relacionados à dificuldade contemporânea de processar a cidadania e aqueles vinculados à representação "idealizada" da mesma -"Cidadania é igualdade para todos, en acho que faz. parte", em que o ser cidadão define-se pela liberdade do indivíduo e pela igualdade, traduzidas pelas seguintes falas: "nós, os pobres, somos cidadãos mais fracos, mais pobres mais bumildes (...) eu acho que todos nós somos". Pode-se inferir que os sujeitos têm uma visão de cidadania idealizada, que se assenta na liberdade e na igualdade do indivíduo (CHÂTELET et al., 1994). A cidadania, fenômeno social complexo, tem sua determinação em pressupostos macroinstitucionais que poderão viabilizar - ou não sua consolidação (FLEURY, 1994; ESCALANTE GONZALBO, 1992; TELLES, 1992; SANTOS, 1979).

\section{Discutindo a sustentabilidade}

Os resultados demonstraram que, mesmo sem reproduzir o conceito de sustentabilidade, os idosos têm noção do mesmo, desenvolvendo atividades práticas e educativas que remetem a ele. Ancoram esse princípio em suas vivências e atividades cotidianas e, nos discursos, observa-se que constroem um modelo explicativo da sustentabilidade centrado nas condições concretas do seu existir: “(...) se toda pessoa que (...) tem uma fazenda (...) conseguir a fazer como o lixão faz um buraco e ali você põe as folhas, põe os frutos (...) na minha própria casa en faço isso, tenho um carrinho, abro assim um pouquinho de terra e tampo (...) é cuidar da natureza, da poluição e vai também ter adubo para as plantas e plantações"; "essas pequenas coisas que a gente faz é que vai sustentar o meio 
Representações sociais sobre educação ambiental...

ambiente, para que ele não perca os benefícios que nos dá". Poucos constroem um discurso da sustentabilidade para além das suas fronteiras fisiogeográficas, como demonstrado nas seguintes falas: “(...) na Amaz̧ônia para que não haja devastação, cortando madeira, tirando madeira e não replantando. Então, eu acho que no caso ai o país tenta sustentar uma coisa, sem atrapalhar a outra".

\section{Discutindo a Educação Ambiental}

Outra providência da lei $n^{\circ}$ 9.795, que instituiu a Política Nacional de Educação Ambiental, foi relacionada ao caráter educacional. Nesse sentido, "a educação ambiental é um componente essencial e permanente da educação nacional, devendo estar presente, de forma articulada, em todos os níveis e modalidades do processo educativo, em caráter formal e nãoformal" (BRASIL, 1999). No ensino formar, entende-se por educação ambiental aquela desenvolvida na esfera dos currículos das instituições de ensino públicas e privadas, que englobam educação básica, educação superior, educação especial, profissional e de jovens e adultos. No âmbito do ensino não-formal, é entendida como ações e práticas educativas voltadas à sensibilização da coletividade sobre as questões ambientais e à sua organização e participação na defesa da qualidade do meio ambiente.

Os entrevistados apontaram a educação ambiental atrelada ao aspecto não-formal de ensino: "é a pessoa freqüentar uma turma, que eles possam dar uma palestra pra gente, né, aprender essas coisas (...) ter uma pessoa ali explicando sobre o ambiente". Outro ponto frisado pelos idosos foi o relacionado à socialização primária, ao contexto familiar: "eu acho que a educaşão ambiental já tem que vim desde criança. Porque se você não ensinar a criança que chupou uma bala tem que procurar um lixo pra jogar o papel, ela vai jogar aonde tá"; "educação não é depois de velho"; "en acho que a educação ambiental tem que vir de casa, principalmente".

Para Dias (2004a), a educação ambiental deve estar presente em todas as etapas, inclusive em casa, mesmo antes da educação infantil. Na escola, molda-se uma nova mentalidade a respeito das relações ser humano/ambiente. Schall (1994) aponta que o conhecimento de conceitos sobre ambiente ajuda as crianças a adquirirem entendimento para o desenvolvimento de atitudes positivas e ações necessárias relacionadas ao ambiente. Por conseguinte, uma nova pedagogia é marcada pela educação ambiental, a qual surge da necessidade de (re)orientar a educação dentro do contexto social e das realidades ecológicas e culturais onde se situam os atores do processo educativo (LEFF, 2001).

É necessário compreender que a educação ambiental é, antes de tudo, educação. Portanto, um processo educativo intencional, contínuo e participativo, que articula teoria e prática nas dimensões sócio-econômicas, políticas, culturais, ecológicas e históricas, objetivando a formação de cidadãos participativos na busca de ações planejadas (RANCHE e TALAMONI, 2005). Alguns depoimentos apontam para esta vertente: "envolve vários setores, né, porque a educação hoje é a base, a nossa base hoje é a educação"; "é o sistema de ensinar o homem (...) um sistema de transmitir para as pessoas como cuidar (...) porque o progresso fez. com que as pessoas entendessem melhor e compreendessem a educação ambiental”.

A degradação também esteve associada às questões de saúde, como evidenciado nas falas: "cada dia que passa tá mais poluido, o pessoal tá arrancando as matas, desmatando, né. A camada de ozônio cada vez aumentando mais (...) num futuro bem próximo nós vamos ter muitos problemas com o ar que a gente respira"; "meio ambiente eu acho que é a sujeira, a poluição (...) tá acabando com a saúde das pessoas". 
Mohr e Schall (1992) indicam que, com a crescente preocupação do homem em relação às questões ecológicas e aos graves efeitos de sua ação predatória sobre o planeta e sobre a própria espécie, a atenção à saúde volta-se para um contexto mais amplo, levando em conta as relações entre esta e o ambiente físico e social.

No que concerne à responsabilidade e atuação concreta, os entrevistados demonstraram esforço no sentido de ensinar, informar e sensibilizar as pessoas mais próximas, principalmente filhos e netos, a respeito de atitudes em relação ao ambiente. "(...) é programa educativo, ensinar como as crianças devem proceder, não jogarpapel no chão"; "(...) en que sou mãe e já sou avó, tem que começar desde cedo a educar a criança (...) e vou passando pra frente, a começar na minha família, é claro".

As políticas ambientais - e conseqüentemente os programas educativos - necessitam incorporar enfoques integradores que transcendam a mera aplicação de conhecimentos científicos (JACOBI, 2003). O grande desafio é trabalhar as questões ambientais a partir de uma perspectiva global e crítica, na direção da construção e do resgate de saberes (SORRENTINO, 1998). A inserção de outros atores, principalmente os idosos, representa a possibilidade de abranger segmentos sociais que podem ter função transformadora, pois, ao serem co-responsabilizados, esses indivíduos tornam-se essenciais para a promoção do desenvolvimento sustentável (TAMAIO, 2000).

\section{A oficina sócio-educativa}

Nos dois grupos trabalhados, surgiu a demanda por uma oficina sobre o tema da pesquisa. Foi realizada, então, a oficina ambiental "Repensando o lixo". O tema foi proposto pela coordenação dos grupos, em conjunto com os idosos e a pesquisadora. Durante as entrevistas, observou-se o interesse dos idosos pelo tema lixo, a partir do que foi elaborada uma oficina de confecção de objetos recicláveis, a saber: uma cadeira com garrafas pet e um jogo de damas com tampinhas de refrigerante. A produção da cadeira foi coletiva, pois os idosos dos dois grupos conseguiram reunir material suficiente para construir apenas uma cadeira. No clube Viver Melhor, os participantes sugeriram que a cadeira ficasse para o grupo e fosse utilizada nos encontros. Já no Fonte de Vida os idosos optaram por levar para casa uma peça modelo e, a partir dela, construir sua própria cadeira.

$\mathrm{Na}$ oficina foram explorados os seguintes temas associados ao lixo: reciclagem, preciclagem ${ }^{5}$ coleta seletiva, como selecionar o lixo, tipos de lixo quanto à composição e formas de destinação final do lixo. Logo após a realização das técnicas de grupo, os pontos relevantes de cada atividade foram discutidos e refletiu-se sobre alguns aspectos importantes para a educação ambiental e a preservação do ambiente.

De acordo com o referencial teórico-metodológico das oficinas sócio-educativas, nosso objetivo foi aumentar o nível de reflexão e sensibilização dos idosos sobre a questão ambiental, bem como conhecer suas crenças, idéias e sentimentos, visando a reflexão, adaptação e/ou

\footnotetext{
${ }^{5}$ Conceito de preocupação dos consumidores em diminuir a produção dos resíduos logo no ato da compra, optando pelos produtos de material biodegradáveis ou recicláveis. $<$ http://pt.wikipedia.org/wiki/Preciclagem> 
Representações sociais sobre educação ambiental...

mudança, e estimulando novas aprendizagens para o enfrentamento da problemática. Tais grupos não se limitam a conhecer as crenças, mas intencionam sua modificação para a transformação de uma dada realidade populacional (AFONSO, 2003).

As técnicas lúdicas e as oficinas de trabalhos manuais foram recursos educativos que visaram aumentar a compreensibilidade da informação, bem como a motivação do grupo. Esses materiais respeitaram a linguagem, o nível educacional e a idade dos idosos, conforme proposto por Afonso (2003). O aspecto educativo do grupo sócio-educativo foi fundamental. As novas informações, o questionamento de mitos e a possibilidade de tirar dúvidas representaram elementos importantes no processo de mudança das representações que os idosos faziam das problemáticas ambientais atuais.

\section{Considerações finais}

Trabalhamos com a educação ambiental, em grupos da terceira idade, reconhecendo a importância do ensino não-formal em todas as áreas do conhecimento e faixas etárias. Tendo em vista que a educação ambiental foi pouco abordada no ensino formal dos idosos, os grupos de terceira idade mostraram-se importantes para a construção deste conhecimento, a troca de experiências e possíveis ações. Os idosos dos grupos Viver Melhor e Fonte de Vida, colocaram, em suas falas, a educação ambiental como componente essencial, principalmente no que diz respeito à sua capacidade de motivar o idoso para o aprendizado, valorizando suas experiências anteriores, desenvolvendo sua criatividade e, sobretudo, despertando o interesse para o ambiente.

Como processo de educação não-formal, a educação ambiental foi apontada pelos idosos dos dois grupos como uma alternativa que deveria estar permanentemente presentes, de forma articulada, em todas as atividades efetuadas pelas duas instituições. No âmbito do ensino não-formal, suas ações e práticas educativas estariam voltadas à sensibilização da coletividade sobre questões ambientais e sua organização e participação na defesa da qualidade do meio ambiente.

Um dos fatores que determinou a execução desta pesquisa foi a possibilidade da inserção dos idosos nas atividades formais e não-formais de educação ambiental, permitindo que eles resgatem seu reconhecimento social, capacidade criativa e potencializem suas possibilidades, entre outros fatores. Alguns idosos associam a velhice à noção de trabalhadores que perderam sua capacidade de atividade e seu reconhecimento social. Assim, nos grupos de terceira idade, a possibilidade de atuar nas práticas ambientais ampliaria sua autonomia numa ação social que poderia beneficiar o próprio idoso e o ambiente no qual ele se insere. 
Miranda, É. S. et al.

Referências

AFONSO, L.; ABADE, F. L.; AKERMAN, D.; et al. Oficinas em dinâmica de grupo na área da saúde. Belo Horizonte: Edições do Campo Social, 2003.

BARDIN, L. Análise de conteúdo. Lisboa: Edições 70, 1977.

BIANCONI, M. L; CARUSO, F. Educação não-formal: apresentação. Ciência e Cultura, Campinas, v. 57, n. 4, p. 20, 2005.

BRASIL. Lei $\mathbf{n}^{\mathbf{0}} \mathbf{9 . 7 9 5}$, de 27 de abril de 1999. Dispõe sobre a educação ambiental. Disponível em: <http://www.presidencia.gov.br/ccivil_03/LEIS/L9795.htm>. Acesso em: 30 maio 2006.

CAMARANO, A. A. Envelhecimento da população brasileira: uma contribuição demográfica. Rio de Janeiro: IPEA, 2002.

CHÂTELET, F.; DUHAMEL, O.; PISIER-KOUCHNER, E. História das idéias políticas. Rio de Janeiro: Jorge Zahar, 1994.

DIAS, G. F. Educação ambiental: princípios e práticas. São Paulo: Gaia, 2004a. Gaia, 2004b.

Ecopercepção: um resumo didático dos desafios socioambientais. São Paulo:

ESCALANTE GONZALBO, F. Ciudadanos imaginários: memorial de los afanes y desventuras de la virtud y apologia del vicio triunfante em la República Mexicana: tratado de moral pública. México: Colmex, 1992.

FLEURY, S. M. Estado sem cidadãos: seguridade social na América Latina. Rio de Janeiro: Fiocruz, 1994.

GADOTTI, M. Perspectivas atuais da educação. São Paulo em Perspectiva, São Paulo, v. 14, n. 2, p. 3-11, 2000.

GOHN, M. G. Educação não-formal e cultura política: impactos sobre o associativismo do terceiro setor. São Paulo: Cortez, 1999.

JACOBI, P. Educação ambiental, cidadania e sustentabilidade. Cadernos de Pesquisa, São Paulo, v. 118, p. 189-205, 2003.

JOÃO, A. F.; SAMPAIO, Â. A. Z.; SANTIAGO, E. A.; et al. Atividades em grupo: alternativa para minimizar os efeitos do envelhecimento. Textos sobre Envelhecimento, Rio de Janeiro, v. 8, n. 3, p. 1-10, 2005.

LAVALlE, A. G. Cidadania, igualdade e diferença. Lua Nova, São Paulo, n. 59, p.75- 93, 2003. 
Representações sociais sobre educação ambiental...

LEFF, E. Saber ambiental: sustentabilidade, racionalidade, complexidade, poder. Petrópolis: Vozes, 2001.

LIMA-COSTA, M. F.; VERAS, R. Saúde pública. Cadernos de Saúde Pública, Rio de Janeiro, v. 19, n. 3, p. 700-701, 2003.

LIMA, G. C. O discurso da sustentabilidade e suas implicações para a educação. Ambiente \& Sociedade, Campinas, v. 6, n. 2, p. 99-119, 2003.

MINAYO, M. C. S. O desafio de conhecimento: pesquisa qualitativa em saúde. 7. ed. São Paulo; Rio de Janeiro: Hucitec-Abrasco, 2000.

MIRANDA, É. S.; MODENA, C. M.; SCHALL, V. T. Educação ambiental: conceitos e ações de idosos do grupo Renascer em São José de Almeida, Jaboticatubas, MG. In:

ENCONTRO NACIONAL DE PESQUISA EM EDUCAÇÃO EM CIÊNCIAS, 5., 2005, Bauru. Atas... Bauru, 2005. 1 CD-ROM.

MOHR, A.; SCHALL, V. T. Rumos da educação em saúde no Brasil e sua relação com a educação ambiental. Cadernos de Saúde Pública, Rio de Janeiro, v. 8, n. 2, p.199-203, 1992.

RANCHE, P. M.; TALAMONI, J. L. B. Reflexões sobre a sustentabilidade e a educação ambiental. In: ENCONTRO NACIONAL DE PESQUISA EM EDUCAÇÃO EM CIÊNCIAS, 5., 2005, Bauru. Atas... Bauru, 2005. 1 CD-ROM.

SANTOS, W. G. Cidadania e justiça: a política social na ordem brasileira. Rio de Janeiro: Campus, 1979.

SCHALL, V. T. Environmental and health education for school-age children: a transdisciplinary approach. Cadernos de Saúde Pública, Rio de Janeiro, n. 10, v. 2, p. 259-263, 1994.

SILVA, L. M. A.; GOMES, E. T. A.; SANTOS, M. F. S. Diferentes olhares sobre a natureza - representação social como instrumento para educação ambiental. Estudos de Psicologia, Natal, v. 10, n. 1, p. 41-51, 2005.

SORRENTINO, M. De Tibilisi a Tessaloniki, a educação ambiental no Brasil. In: JACOBI, P. (Org.). Educação, meio ambiente e cidadania: reflexões e experiências. São Paulo: SMA, 1998. p. 27-32.

SPINK, M. J. Desenvolvendo as teorias implícitas: uma metodologia de análise das representações sociais. In: GUARESCHI, P. A.; JOVCHELOVITCH, S. (Orgs.). Textos em representações sociais. 7. ed. Petrópolis: Vozes, 2002. p. 117-145.

O conceito de representação social na abordagem psicossocial. Cadernos de Saúde Pública, Rio de Janeiro, n. 9, v. 3, p. 300-308, 1993. 
Miranda, É. S. et al.

TAMAIO, I. A mediação do professor na construção do conceito de natureza. Campinas, 2000. Dissertação (Mestrado) - Faculdade de Educação, Universidade de Campinas.

TELLES, V. S. A cidadania inexistente: incivilidade e pobreza: um estudo sobre o trabalho e a família na Grande São Paulo. São Paulo, 1992. Tese (Doutorado) Departamento de Sociologia, Faculdade de Filosofia, Letras e Ciências Humanas, Universidade de São Paulo.

UCHÔA, E. Contribuições da antropologia para uma abordagem das questões relativas à saúde do idoso. Cadernos de Saúde Pública, Rio de Janeiro, n. 19, v. 3, p. 849-853, 2003.

VERAS, R. País jovem com cabelos brancos: a saúde do idoso no Brasil. 2. ed. Rio de Janeiro: Relume Dumará, 1994.

ZIMERMAN, G. I. Velhice: aspectos biopsicossociais. Porto Alegre: Artmed, 2000.

Artigo recebido em julho de 2006 e aceito em fevereiro de 2007. 